\title{
Spectrum Imaging Analysis of Secondary Phases in Aluminum Alloy 6063
}

\author{
S.R. Claves and M. Watanabe \\ Dept. of Materials Science and Engineering, Lehigh University, Bethlehem, PA 18015, USA
}

As-cast aluminum alloy (AA) 6063 contains $\beta-\mathrm{Al}_{9} \mathrm{Fe}_{2} \mathrm{Si}_{2}$ particles that form a near-continuous network along grain boundaries. These intermetallics often exhibit "branching", where multiple particles form adjacent to one another (Fig. 1). Previous experiments determined the threedimensional (3D) morphology of $\beta$-platelets using a dual-beam focused ion beam (FIB) instrument [1]. The present research analyzed the chemical composition of the AlFeSi phase and the surrounding aluminum solid solution.

A thin foil specimen for analytical electron microscopy (AEM) containing several $\beta$-AlFeSi particles was prepared by the FIB in-situ technique. Images and $\mathrm{x}$-ray spectra were initially acquired using a JEOL 2010F AEM. The intermetallics were correctly identified as the $\beta$-phase (Fig. 2A), while the region between them contained a high concentration of silicon (Fig. 2B). Specific regions were analyzed via spectrum imaging performed on the VG HB 603 AEM operated at $300 \mathrm{kV}$. The highlighted area (Fig. 1C) was mapped with 128x128 pixels; acquisition time per pixel was $100 \mathrm{~ms}$.

The $\zeta$-factor method [2] was applied to determine the AEM specimen thickness (Fig. 3) in order to calculate absorption corrected compositions (Fig. 4 - top row). Iron has a negligible solubility in aluminum and segregates entirely to the $\beta$-AlFeSi phase. Small, $150 \mathrm{~nm}$-sized silicon particles precipitated between the intermetallics. Multivariate statistical analysis (MSA) was subsequently performed to reduce the random noise found in the spectrum imaging data. This process identifies statistically significant compositional distributions and enhances weak x-ray signals efficiently [3]. The composition maps reconstructed by removing noise (Fig. 4 - bottom row) are virtually unchanged for the major elements (Al,Fe,Si). However, the distributions of the minor constituents $(\mathrm{Mg}, \mathrm{Mn})$ are significantly improved. The images clearly indicate definitive microstructural trends.

Magnesium exists up to $2.0 \mathrm{wt}$. \% in the $\beta$-AlFeSi phase, while the remainder is present in aluminum solid solution. The $\mathrm{Mg}$ concentration in the region between the intermetallics $(\sim 4.5 \mathrm{wt} . \%)$ is much higher than the average for the alloy $(\sim 0.6 \%)$. This localized volume originates from the $\mathrm{Al}$ dendrite tips, which, during casting, are the last to solidify and hence possess the highest solute content.

The manganese compositional map exhibits low noise even though the concentration is less than 0.5 wt. \%. Although it possesses some solubility in aluminum, Mn segregates entirely to the $\beta$ intermetallics, where it substitutes for iron. Hence, the distributions of these two elements, shown in the compositional maps, are qualitatively very similar. Finally, the MSA results were used to accurately determine the chemical composition of the $\beta$-AlFeSi phase - Al: 52.8 wt. \%, Fe: 31.4, Si: 13.4, with small amounts of Mg: 1.9 and $\mathrm{Mn} 0.4$ [4].

\section{References}

[1] S.R. Claves et. al., Microsc. Microanal. 10 (Suppl. 2) (2004) 1138.

[2] M. Watanabe and D.B. Williams, J. Micros., in press (2006).

[3] M.G. Burke et. al., J. Mat. Sci., accepted (2006).

[4] This research was supported by the NSF under grants DMI-0115146 and DMI-115330. 

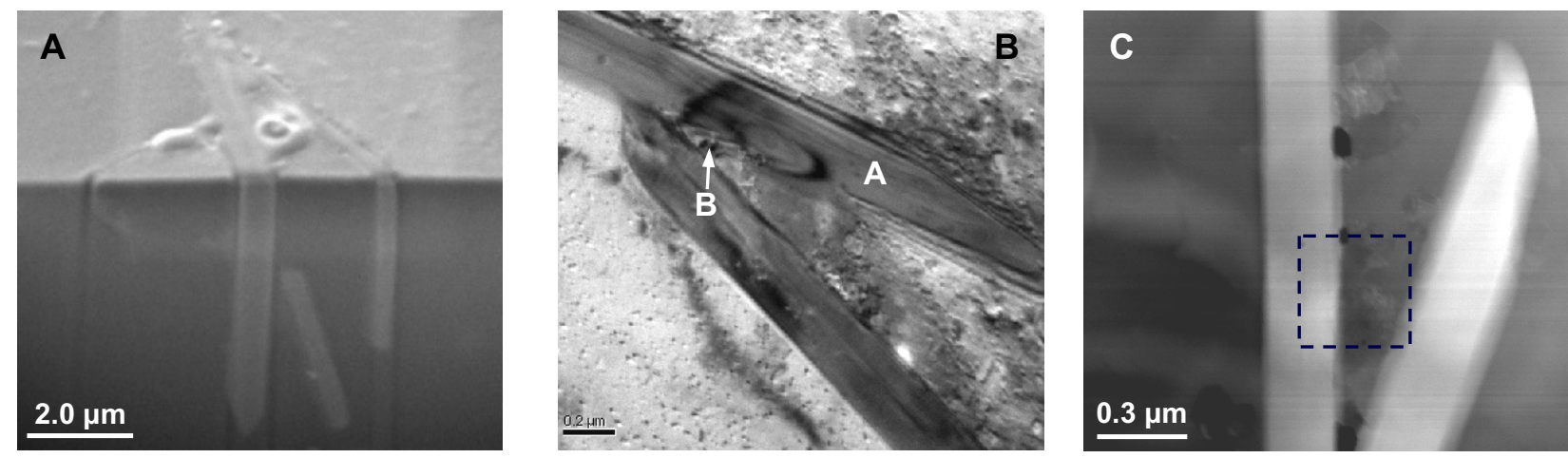

Fig. 1: Micrographs of branched $\beta-\mathrm{Al}_{9} \mathrm{Fe}_{2} \mathrm{Si}_{2}$ particles in aluminum alloy 6063:

A) FIB electron image: 2 perpendicular planes reveal platelet morphology.

B) TEM: locations for EDS spectra (Fig. 2); high solute content between intermetallics.

C) DF-STEM: area selected for spectrum imaging compositional analysis (Fig. 4).
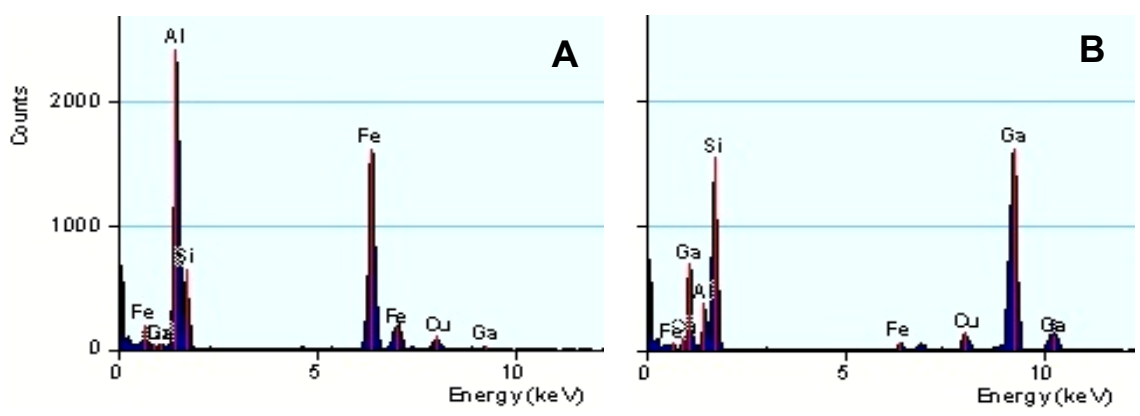

Fig. 2: EDS of A) $\beta-\mathrm{Al}_{9} \mathrm{Fe}_{2} \mathrm{Si}_{2}$ and $\mathrm{B}$ ) area between $\mathrm{AlFeSi}$ particles. Locations of spectra are shown in Fig. 1B.

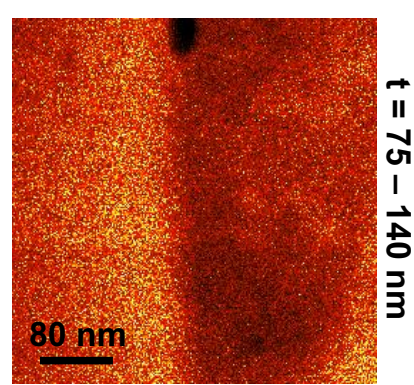

Fig. 3: TEM specimen thickness variations.

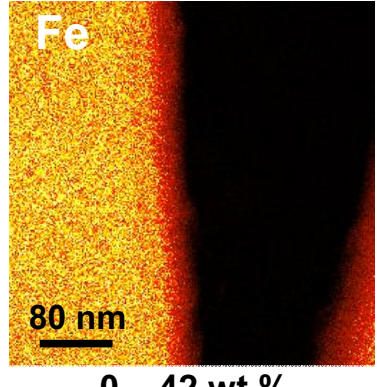

$0-42$ wt. $\%$

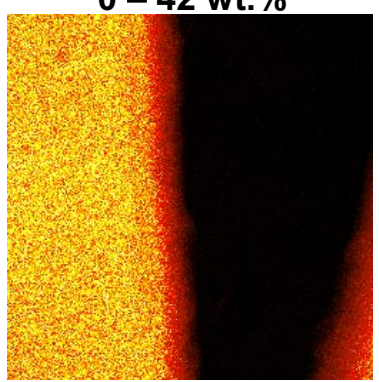

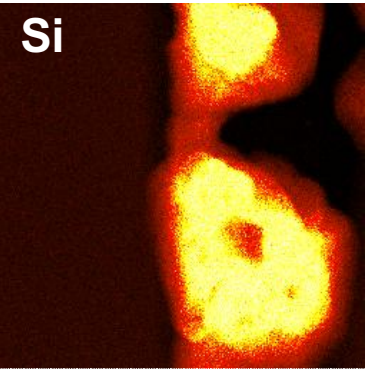

$0-100 \%$

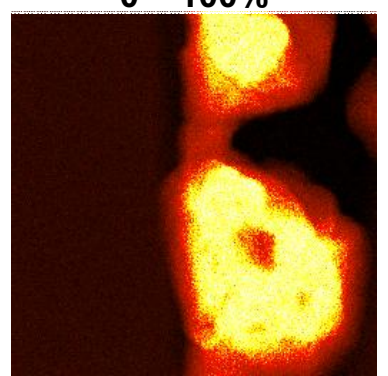

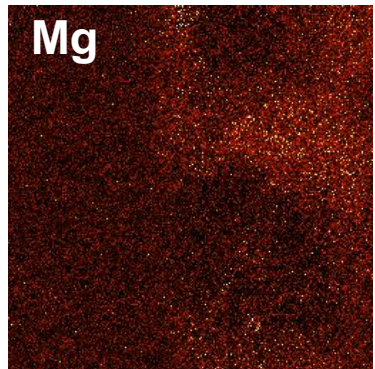

$0-5.0 \%$

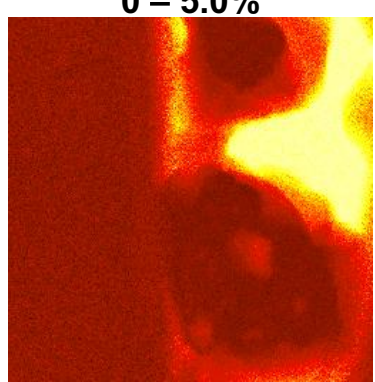

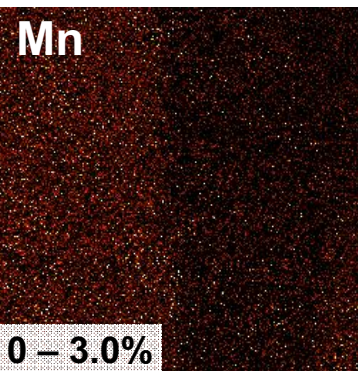

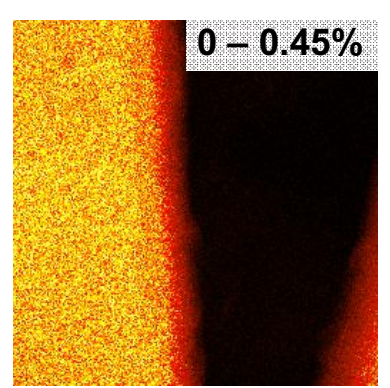

Fig. 4: Composition maps of area highlighted in Fig 1C.

Top row $-\zeta$-factor method | bottom row - reconstructed after MSA. 